\title{
Xenotransplantation of the Pancreas: A Reality Check of Its Historical Emergence
}

\author{
Cyprian Weaver*
}

Department of Medicine, University of Minnesota, Minneapolis, USA

*Corresponding author: Cyprian Weaver, Department of Medicine, University of Minnesota, Lillehei Heart Institute, Cancer \& Cardiovascular Research Building, 2231 6th St. SE, Minneapolis, MN 55455, USA, Tel: 612-625-2908

\begin{abstract}
Recent advancements being made in the humanization of Crispr-based gene-edited animals have now provided a sophisticated molecular platform for exogenic organ production and xenotransplantation. Although this amazing and novel medical step into the future holds significant therapeutic promise for pancreas xenotransplantation presently impeded by lack of sufficient donors, its origins arose in an era that is often portrayed as an age of medical quackery and iatrogenesis. The present study reexamines the historical and cultural context in which the first pancreatic xenografts which preceded any attempt at allotransplantation emerged as an interventional force within clinical medicine during the mid-1800s into the early part of the 1900s. More specifically, it focuses on the advances and scientific findings that arose historically as a consequence of the newly diagnosed state of diabetes mellitus in the mid-1800s. Known throughout previous centuries yet ever evasive as a defined dysfunctional complex within carbohydrate metabolism, diabetes was initially challenged by its tenuous association with the pancreas. Once correlated however, dynamics were set into motion whereby the then current theory of internal secretion would initiate a struggle between hormone replacement theory per se and organ replacement. Initially the isolation and application of the potential anti-diabetic factor took the form of crude preparations of pancreatic 'juice' or the application of raw animal pancreas both via oral consumption as well as xenogeneic grafting. Both interventions proved ineffective. Ultimately the more refined extracts derived from duct-ligated pancreas to reduce the contaminating exocrine parenchyma led to the isolation and therapeutic use of insulin. The historical backdrop provides an insight to legitimate concerns of physicians for patients balanced by their willingness to employ unknown and novel treatments to rescue patients from the dreaded consequences of diabetes.
\end{abstract}

\author{
Keyword \\ Diabetes, Pancreas, Xenotransplantation, Insulin, Islets, In- \\ ternal secretion
}

\section{Introduction}

Although diabetes as a disease characterized by excess loss of urine and its 'sweet' quality was known in the East for centuries and named diabetes by Aretaeus in $2^{\text {nd }}$ century $A D$, it was not until the $17^{\text {th }}$ century that the characteristic quality of urine and blood began to take on clinical significance. While Thomas Willis in 1679 noted the "wonderfully sweet" quality of the evaporated residue of diabetic urine that "tasted like honey" [1], William Cullen noted in 1769 that there was a diabetic urine which was insipid to the taste and drew a distinction between the two by designating diabetes "mellitus" (honey) referring to Willis's observation and diabetes "insipidus" referring to his observation of tasteless urine from polyuric patients [2]. It was the observations of Matthew Dobson in 1776 however that identified the sweetness as sugar that was present in the blood as well as the urine of diabetic patients since fermentation occurred with the addition of yeast [3]. Later John Rollo (1797), suggested an "animal diet" to treat patients with excessive blood sugar or hyperglycemia (Figure 1) [4]. In 1815 Chevreul identified the urine sugar as glucose which he held to be a byproduct upon digesting plants (Figure 1) [5]. Later, Claude Bernard (1848) would experimentally demonstrate that glucose is a normal constituent of the blood which was derived from hepatic stores of glycogen independent of dietary nutrients of sugar and carbohydrates [6], and absorbed 
by the intestines, converted to glucose and released into the circulation upon need during the fasted state.

\section{Pancreas and Diabetes Connection}

Despite this progressive trend in characterizing the disease, its relation to the pancreas remained unrecognized until the 1870s when the French physician, Apollinaire Bouchard observed the occurrence of pancreatic lesions in post-mortem tissues of diabetics [7]. In late 1870 's a further distinction would prove useful in clinically defining the diabetic state. Etienne Lancereaux whose work - Traite de Pathologie - and keen observations intimated a potential relationship between diabetes and the pancreas made a further distinction in 1877 between two types of diabetes - one he referred to as diabete maigre (skinny diabetes) and the other as diabete gras (fatty diabetes) [8,9], which was later confirmed experimentally in 1888 [10]. Diabete gras (fatty diabetes) was noted to respond to dietary intervention while diabete maigre (skinny diabetes) failed to respond to any therapeutic intervention and resulted in death. Following Murray's clinical report in 1892 that a thyroid extract could palliate myxedema, nascent speculation grew as well that the pancreas might be involved in carbohydrate metabolism in a similar manner via an internal secretion. The focus on pancreatic diabetes was keenly reinforced although not immediately by the work of Minkowski and Mering in 1889, when they published their work on pancreatectomy in dogs which resulted in diabetes (Figure 1). Their experiment clearly demonstrated that following total extirpation of the pancreas diabetes mellitus ensued and lasted until the death of the dog [11]. They also determined elevated levels of sugar in the urine as well as the end-phase course of diabetes with the formation of acetone in the urine. This was further established by the experimental work
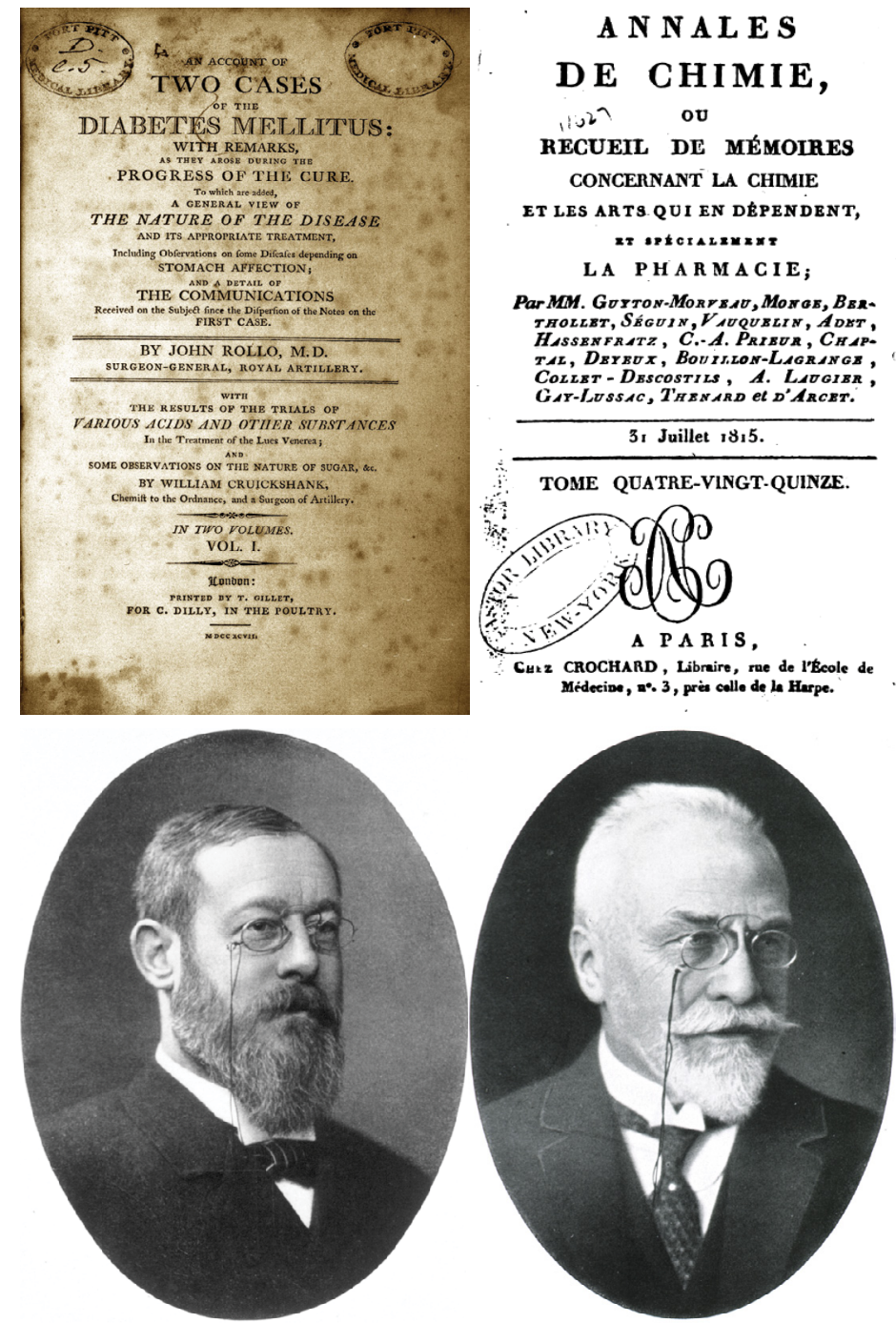

Figure 1: Top left. Frontispiece of John Rollo's work which described the first diabetic diet used as a therapeutic approach to diabetes. Source: T. Gillet, for C. Dilly, in the Poultry in London, 1798. Top right. The title page from Chevreul's article reporting for the first time that the sugar contained in diabetic urine was glucose. Source: Ann. Chim., 1815. Bottom left. Jacob von Mering. Source: Public Domain. Bottom right. Oscar Minkowski. Source: U.S. National Library of Medicine. Mering, and Minkowski were the first in 1889 to clearly demonstrate that total removal of the pancreas from the dog resulted in fulminant diabetes marked by glycosuria and eventually death. Each had made outstanding contributions to diabetology before their collaboration. Mering had produced experimental diabetes by the use of phloridzin while Minkowski had been the first to characterize beta-hydroxybutyrate in diabetic coma. 
of Hedon and Lancereaux and Thiroloix in 1892. Both groups independently approached the experimental design in such a way as to try and characterize the intrinsic secretion of the gland. Both dissected a segment of the duodenal region of the canine pancreas and grafted that portion ectopically under the skin of the abdomen taking care to rejoin the vascular supply of the graft. The wound healed except for a small orifice that served as a fistula. After some time, the remaining pancreas was removed but no diabetes followed. However, when the grafted portion was removed, there was an immediate onset of polyuria and glycosuria indicative of diabetic changes which led to the death of the animal. Lancereaux and Thiroloix concluded that given: "this experiment, repeated many times, having always yielded the identical results, it must be admitted that it is not the external glandular secretion, but a kind of internal secretion, which becomes the cause of this glycosuria" [12]. Hedon likewise concluded: "The theory that the pancreas functions as a blood vascular gland seems to me to be firmly established by these transplant experiments" [13]. Hedon experimented as well using transplantation and parabiosis experiments between pancreatectomized and normal dogs that restored normal metabolism to diabetic dogs and urgently suggested a role of internal secretion within the pancreas [14]. Exactly how much of the pancreas could be removed without the onset of glycosuria and diabetes remained unclear. In Minkowski's later work (1893) he found that with one-fourth to one-fifth of the gland remaining in the dog, the animal remained normoglycemic. Even in cases where the remainder of the gland was without ductal connection to the duodenum and the animal challenged with 500-1000 grams of carbohydrate and 100-200 grams of cane sugar there was no evidence of glycosuria [15]. Minkowski however was unwilling to state how much of a fragment was necessary to prevent diabetes because of the complexity arising from the nutritional status of the fragment. Several years later Harley (1895) observed that one-sixteenth of the gland as an isolated fragment remaining within the animal was sufficient to prevent glycosuria [16].

\section{The Means of Treatment}

Once the pancreas became identified as potentially having an anti-diabetic factor numerous clinical attempts were made to apply, as in the case of the thyroid, an extract of the organ to attenuate the pathological features which at this point were beginning to be recognized as symptomatic of the disease. Crude preparations of pancreatic juice, were concocted for their patients by Mansell-Jones [17], and Wood [18] while Mackensie administered an alcoholic form of pancreatic extract (liquor pancreaticus) [19] all in 1893. While Hale White, also in 1893, initially treated his young patients with fresh, raw sheep pancreas, he too resorted to an alcoholic pancreatic extract when the fresh gland proved ineffective
[20]. Later from the work of others and their lackluster results as well as his own attempts, which promoted any significant changes in urine volume, specific gravity and sugar content, Hale White himself began to doubt if any benefit arose from such a regimen.

Questioning the route of administration, McNamara (1894) who was not a diabetologist but a surgeon, suggested to clinicians working with diabetics to consider administering uncooked pancreatic extract via the rectum and if required through the rectal veins themselves. His rationale rested on the supposition that the "mysterious sugar restraining element acted directly on the liver and would be destroyed in the general circulation" [21]. Other unusual variants of application continued to be explored including one in which the final step of treatment led to the first recorded pancreatic xenograft. P. Watson Williams, a senior assistant physician at the Bristol Royal Infirmary decided to implement "fresh lines of treatment as at least affording some chance of increased control over this disease" [22]. The patient was a 15-year-old male who had been admitted in July of 1894 because of the onset of physical wasting and increasing acute weakness and upon examination, sugar in the urine which persisted despite a dietary restriction and measured over several days. It was not uncommon at this time that patients waited some time before consulting a physician with the result that wasting was at an advanced stage (see Figure 2 and Figure 3). Although initially fed freshly minced pancreas for one week followed by several days in which liquid pancreatic extract was administered with all meals, and succeeded yet by another week of both oral extract as well as extract given by daily subcutaneous injection, no change in symptoms ensued and the polydipsia, polyuria and urine glucose only increased. Variants of this regimen continued over the next several months including subcutaneous injection of pancreatic extract processed according to the specifications of Brown-Sequard in Paris - the notable advocate of organotherapy, and still later with orchitic fluid from a young bull without any signs of remission. Having exhausted all other means in December of the same year, Williams and his surgeon colleague, William Harsant, prepared the boy for implantation. Three pieces of freshly slaughtered and aseptically prepared sheep pancreas were implanted subcutaneously in the regions of the chest and abdomen and the wounds closed and dressed and appeared to be healing. Despite this, the patient continued to decline and died three days later in a diabetic coma. Watson Williams commenting on the postmortem noted evidence for the case being correctly diagnosed as pancreatic diabetes given the extreme atrophy gland that had been largely replaced by connective tissue and with a loss of the "secreting structure" also noted that the failure was possibly due to the fact that the sheep had been bled prior to collection of its organ. If he was to repeat the operation he would opt for an anesthetized living animal. A few 

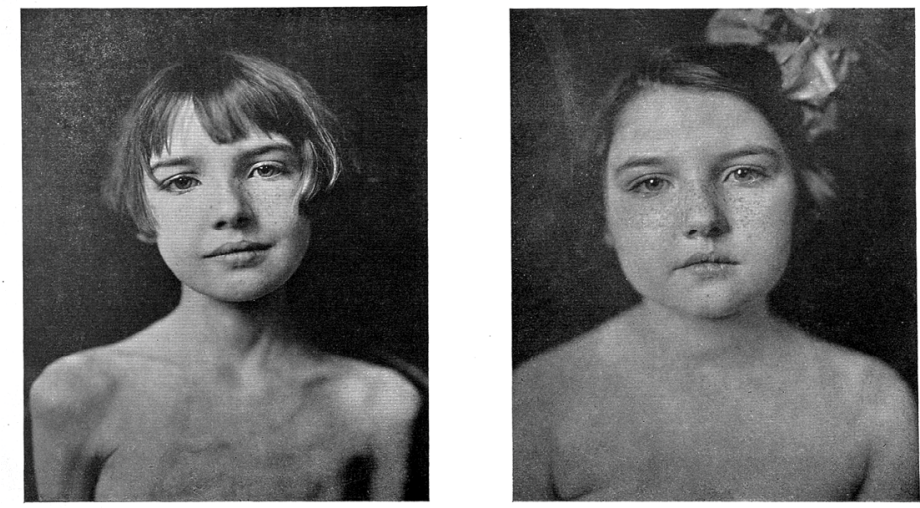

Case VI

Before Insulin

Case VI

4 Mos. After
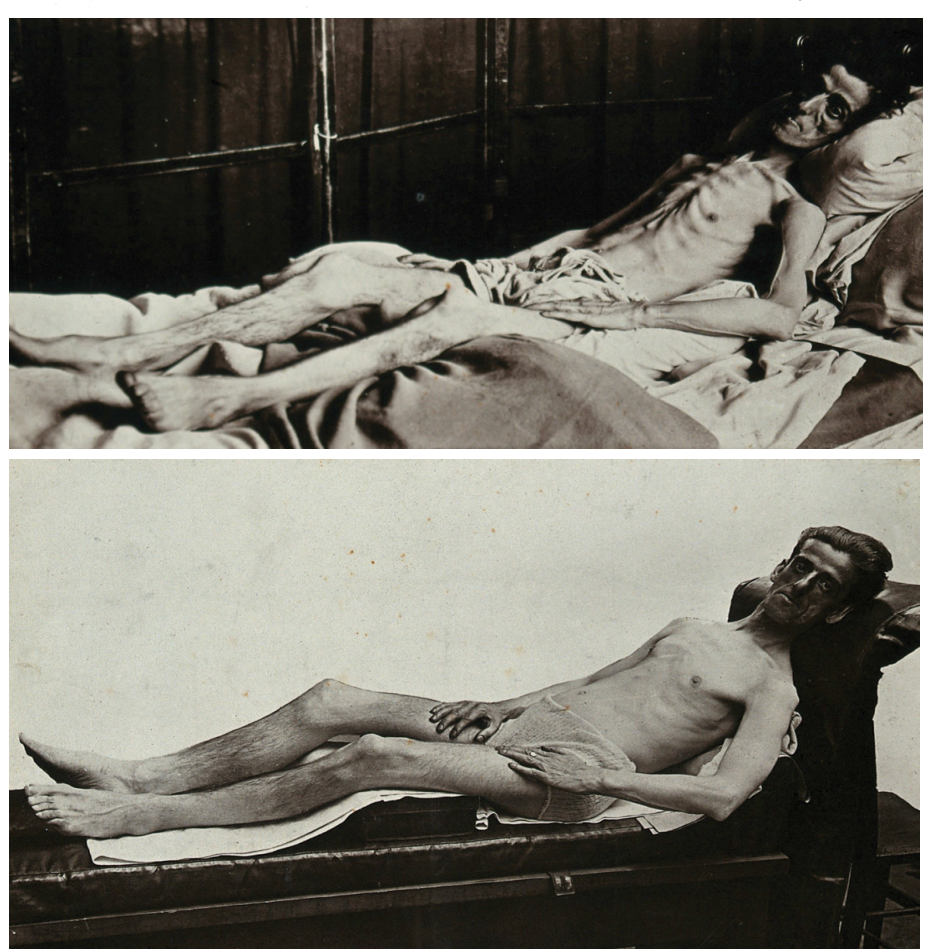

Figure 2: Top: Many adolescent diabetics faced dismal futures without the aid of insulin therapy that reversed the emaciation accompanying unstable carbohydrate metabolism. Middle and Bottom: As with many of the early cases presenting with diabetes, the initial loss of weight and stamina brought patients to seek help. Even those diabetics who were older often presented in untreated cases with extreme loss of weight. Polyuria often resulted in dehydration that contributed to the weight loss combined with the breakdown of muscle tissue. With the newly discovered insulin therapy most cases responded dramatically to the stabilization of weight and muscle health as shown in the patient above. Source: CC By Credit: Wellcome Collection.

years later he acknowledged as well that the failure of the procedure "might be attributed to my reluctance to resort to any operative treatment in a bad case of diabetes until it was very evident that the patient was approaching a fatal termination [23].

Following this first attempt at pancreatic xenotransplantation, James Allan reported in a series of letters in the British Medical Journal of 1903 his attempt to normalize the glucose dysregulation in his patient by means of a glandular implant. His goal was to harness the putative effect of its internal secretion: "by implanting pancreas we might get a bigger supply of the sugar-destroying substance which would be helpful in cases when the patient's pancreas was normal but unequal to the task of coping with the surplus of sugar $[24,25]$. With the assistance of his surgeon colleague Dr. Bar- low, a pancreas removed from a cat was transplanted subcutaneously into his male patient. Unfortunately the patient's died two weeks later and attributed to a diabetic coma. The necropsy in this case, unlike that of Williams's patient, showed the pancreas to be "quite healthy to the naked eye" [26].

Although not published until later as a historical account, the Australian physician, John Ramsay, Surgeon Superintendent at the Launceston General Hospital, Tasmania, undertook the very first procedure of a human pancreatic allograft. Ramsay removing several inches from the tail region of the gland from a male cardiac patient who had suddenly and unexpectedly died, transplanted the tissue into the subperitoneal tissue of his 59-year-old diabetic patient [27]. Initially, the patient's glycosuria levels decreased and on the seventh day 


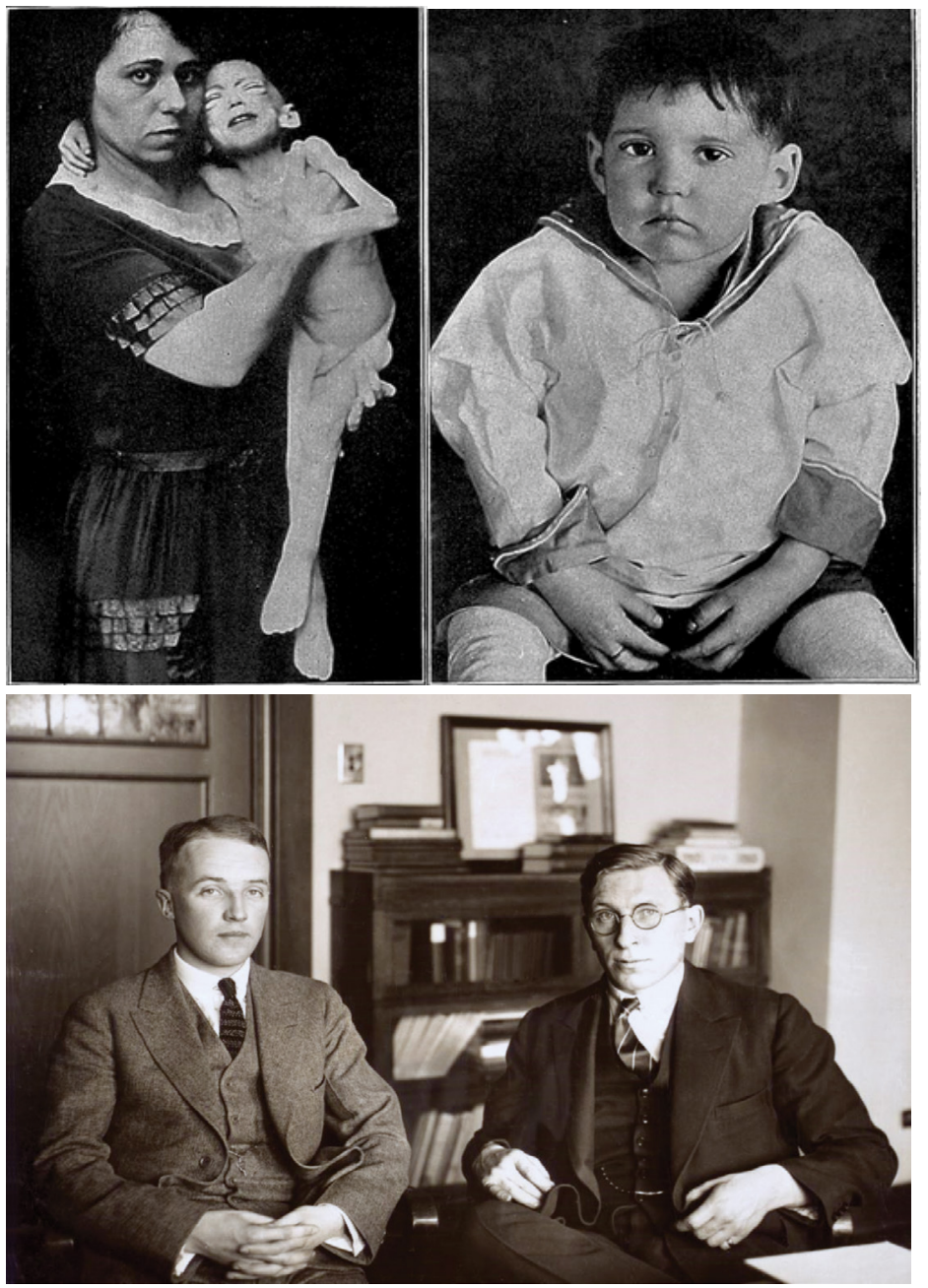

Figure 3: Top: The effect of perinatal diabetes was devastating but with the advent of insulin many babies would have a greater chance of survival as in the subject shown above before and after insulin treatment. Source: Wellcome Collection. Bottom: Charles H. Best and Frederick Grant Banting, taken around 1924. Banting a Canadian physician was given the American physiology student Charles Best as an assistant by J. J. R. Macleod who was Professor of Physiology at the University of Toronto where the research leading to the discovery of insulin was conducted with the further assistance of James Collip who was the biochemist in the group. Source: MS. COLL 76 (Banting) Sb 1, Bx 3, p. 171. Thomas Fisher Library, University of Toronto.

completely negative. Subsequently however, the levels began to rise and upon discharge a month later was at the preoperative levels of $6 \%$. Ramsay later noted his regret that the graft contained the exocrine digestive cells which may have compromised the outcome. As a phenomena found in the transplantation of endocrine glandular tissue, the transient lowering of urine glucose no doubt was in response to the insulin initially released by the freshly grafted tissue.

In 1924, following the earlier dismal results of xenografting but acting upon their underlying theoretical considerations of functional restoration, the British surgeon Frederick Pybus undertook the first recognized and published pancreatic allotransplant. Pybus, an assistant surgeon at the Royal Victoria Infirmary in Newcastle upon Tyne, had undertaken as a final attempt following the failure of adrenal extracts as well as xenogeneic transplants, to reverse two cases of $\mathrm{Ad}$ dison's disease by allografting the gland. One patient showed some improvement while the other died. Faced with much the same dilemma with regard to pancreatic extracts but aware that some experimental evidence supported the observation that 'pancreatic grafts could live in a new environment" and that "the homoplastic method appeared well worthy of trial," Pybus undertook two pancreatic allografts [28]. The pancreas of a recently deceased patient was divided into two parts and transplanted within the subcutaneous tissue of the abdominal wall of two diabetic male recipients in their thirties. One patient died three months later while the second survived for three years. Neither patient however recovered from their diabetic state. Pybus concluded that: "Not much can be said about the principles of grafting, but it seems that until we are able to understand them (and I feel we do not understand them at present, especially the chemical factors), then we must continue to fail in such operations, although they may appear the most rational treatment for the diseases for which they were attempted" [28]. Although overlooked, evidence had been provided earlier that demonstrated 
allotransplantation of the pancreas in animals had met with failure. Donato Ottolenghi, from the University of Turin Institute of General Pathology, found an earlier report by R. Alessandri (1896-97) in which he had transplanted pancreatic tissues into spleen and liver inconclusive and therefore undertook similar allograft experiments published in 1901 on the guinea pig. He transplanted small pieces of pancreas into several sites including the peritoneal cavity, spleen, liver and under the skin - the location of which would make no difference in the results [29]. He followed the post-surgical period up to 45 days examining the gross and microscopic appearance of the implants at intervals to derive a sequential record of the changes. As might be expected he observed core necrosis of the implants due to lack of oxygen to the non-vascularized tissues surrounded by peripheral tissues containing viable and even karyokinetic cells that were seen largely in ductular and cystic-like parenchyma. However, the mitosis was insufficient to elicit any regeneration. In conclusion, Ottolenghi found that "in relation to the Langerhans Islands, the results obtained so far are not decisive; what I observed would bring me only to believe that, in transplantation, they are subject to rapid necrosis" [29]. Parallel attempts to restore normoglycemia in animals with pancreatic extracts were shown as well to produce little or no reversal. While Tiberti's experiments reported in 1909 more or less indicated that onset and degree of glycosuria in partial pancreatectomized dogs generally depended on the amount of the pancreas removed - in the totally pancreatectomized animals those that were "treated with nucleoprotein or pancreatic extract did not exert a decisive influence on the course of glycosuria" [30].

\section{The Discovery of the Islet}

In 1869, a young medical student at Friedrich Wilhelm University presented the results of his medical dissertation which was a microscopic study of the pancreas (Figure 4). His choice of rabbit pancreas chosen out of expediency would prove providential since unlike

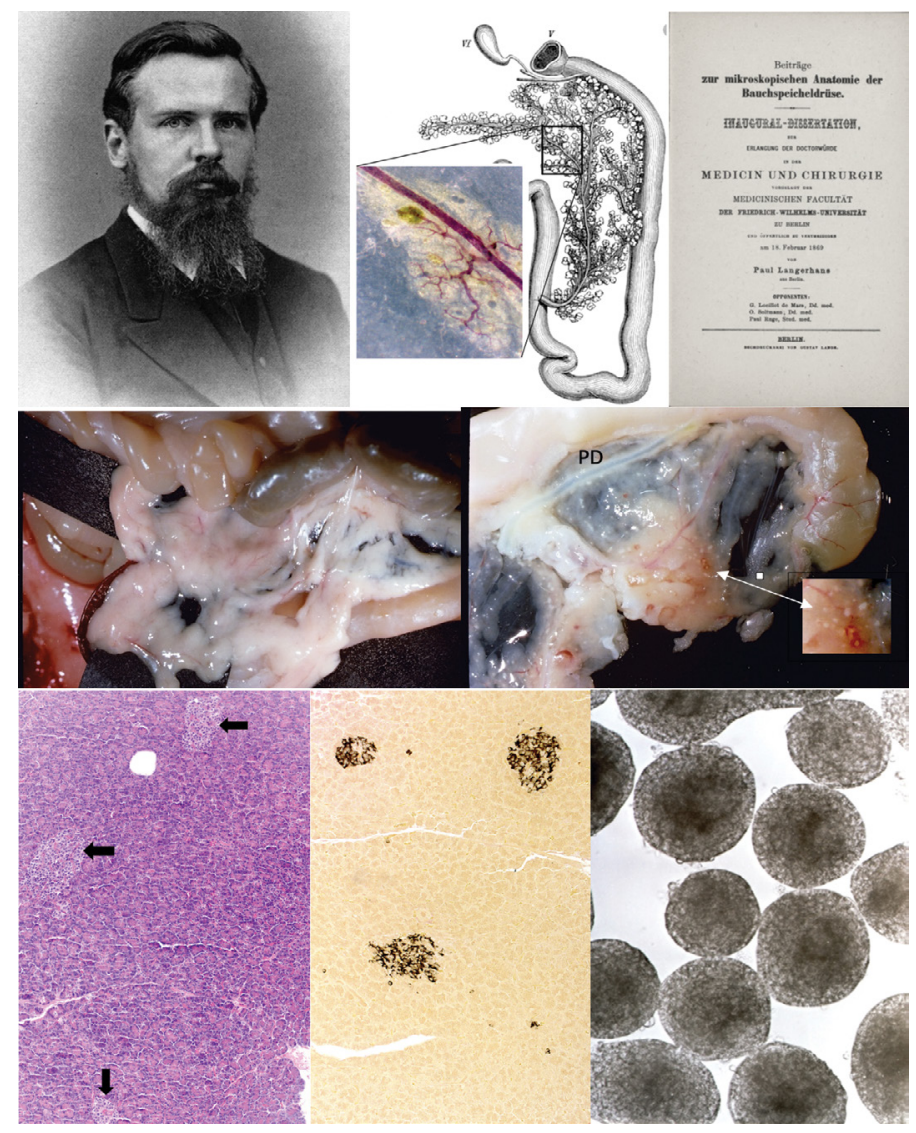

Figure 4: Top Left: Paul Langerhans aged 31 taken in 1878. Source: Public Domain. In 1867 he began his study of the rabbit pancreas as a model for viewing the islets within the highly diffuse organ (Top, middle). Injection of the vascular system highlighted islets within the predominant acinar tissue. The inset shows a similar example of this technique where the islets appear as greenish spherical profiles. Source Drawing: “Das Kaninchen”, U. Gerhardt, 1909. Top, right. Langerhans' thesis published in February, 1869. Source: Public Domain. Figure 4 Middle row: Left (normal) and right (atrophied) panels show the effects of ductal ligation on rat pancreas where the pancreatic duct is ligated and after several weeks acinar atrophy noninflammatory lipomatosis reveal the position of islets which remain unaffected (inset). The pancreatic duct (PD) which was ligated cannot be seen in the normal gland but becomes readily visible in the atrophied organ. Figure 2: Bottom row: Left panel shows appearance of islets microscopically (arrows) and stained with routine H\&E. Their elusive appearance was a challenge for the early observers to ascertain their structure and function. With modern immunohistochemical techniques their location is made far easier as shown in the middle panel where the islets are stained for insulin. Right: Islets are spherical cellular aggregates that vary from $50-500 \mu \mathrm{m}$ in diameter clearly seen when isolated. Source of micrographs: ${ }^{\circ} \mathrm{Cyprian}$ Weaver, 2019. 
many lower mammalian forms the rabbit pancreas is a widely diffuse organ in which islets are easier to observe macroscopically. He aided his investigation by vascular injections of Berlin blue that further enhanced islet tissue within the exocrine parenchyma. In addition to the detailed analysis of the exocrine parenchymal cells he described: "Small cells having an unusual homogeneous content, with polygonal shape and containing a round nucleus without a nucleoli and usually lying in twos or small clusters" (Figure 4) [31]. Unknowingly, he had described the pancreatic endocrine portion of the gland the islets - but whose function would remain a mystery for the next two decades. The islets as the source of an internal secretion within the pancreas, that is to say an "endocrine secretion" was first defined and described by the work of Laguesse some 24 years following Langerhan's initial description. In his 1893 work, he was the first to use the term: islets of Langerhans in his title and the first to treat the islets technically as the 'islets of Langerhans', a salient contribution because it would focus attention on a part of the pancreas that was morphologically and physiologically distinct from the exocrine parenchyma of the gland even though it had not yet been experimentally defined as such and histologically was poorly characterized [32]. Furthermore, with this initial work, Laguesse was the first investigator to attribute an internal secretion to the islet and thus set a pivotal focus on the endocrine nature of the islet - at least nominally. It should be noted here however, that Truhart made a claim in 1904 that Laguesse was not the first investigator to attribute an internal secretion to the cells of the islet. He attributed this distinction to a young Russian physician, Claudia Ulesko whom he claimed "deserved the credit of having first established the hypothesis that the Langerhan's cell bodies are purely epithelial structures to which an independent character must be granted based on anatomy as well as function" [33]. He based this exclusively on a statement from Ulesko's 1883 inaugural thesis published in the same year in Vrach (The Doctor) that dismissed the lymphoid theory of islet cells because "the so-called follicles of the pancreas are not the formations of lymphatic origin, but the very parts of the organ related to its specific activity" [34]. The italicized portion above is the sole evidence interpreted by Truhart - and possibly by Ulesko herself for the endocrine nature of the cells that would become known as islet cells some ten years later with Laguesse's designation. While this putative 'first discovery' has been lost to history either appropriately or unjustifiably, the discovery of the endocrine nature of the islet cells at this time would prove crucial to their implementation for xenotransplantation.

It was some 30 years earlier that Claude Bernard (1856) had hypothesized the existence of internal secretions in not only the liver but in ductless glands - those glands which carried with them the crucial feature of being 'blood vessel glands'('Blutgefaessdru- sen') defined earlier in the 1840s and now being used to connote ductless glands that gave rise to an internal secretion transported into the general circulation [3537]. Most importantly, the enthusiasm for adopting this system as a palliative means of supplementing diseased glands was being actively promoted on the clinical front by Murray (1892) who adeptly demonstrated that administration of thyroid extracts could alter the pathological sequelae of myxedema [38]. On the popular front Brown-Sequard, the renowned and controversial neurophysiologist, was promoting the use of extracts derived from animal organs, especially glands, for the treatment of disease and which he was formulating as organotherapy. He had testified earlier in 1889 that the self-injection of testicular extracts could restore vigor lost by the vicissitudes of aging and later in 1893 that the fatal effects of total adrenalectomy could be deferred by infusion of normal blood presumably carrying adrenal secretion $[39,40]$.

Laguesse's work was quickly noted and found support in Schafer's observations reported in 1895, in that: "The only fact that appears certain in connection with the manner in which the pancreas prevents excessive production of sugar within the body is that this effect must be produced by the formation of some material, secreted internally by the gland and probably by the interstitial vascular islets [41]. Nevertheless, it was largely the observations and analyses of pathological states of the organ that led to another Russian, the physician Leonid Ssobolew, to conclude in his experiments (1900-02) that the islets which lacked ducts and were highly vascularized were also the anatomical and functional structures within the pancreas that controlled carbohydrate metabolism $[42,43]$. This was the position quickly adopted by Sauerbeck and his association of the islets with diabetes in 1902 [44,45] as well as Opie who in 1901 focused on the relationship of diabetes to lesions of the pancreas and concluded that the hyalinization which is strictly limited to islets in the pancreas of diabetics provided clinical evidence that favored a causal relationship between this destructive lesion of the pancreas and diabetes [46]. Meanwhile, the Belgian clinician, Jean DeMeyer (1909) investigated the glucose lowering properties of the internal secretion and from his experimental work on the effects of the internal secretion on the kidney he became the first to suggest a name for the active component: "We think we can relate this clinical notion to the experimental results we have obtained: We believe that we have demonstrated the internal secretion of the pancreas, insulin if we want to give it a name" [47]. But it was not until Gley's observation in 1905 but only reported in 1922 that this internal secretion was the source of an anti-diabetic factor [48]. Furthermore, Gley suggested that the reason why previous attempts to treat diabetes with pancreatic extracts had failed was because this internal secretion was destroyed during extract preparation by elements 


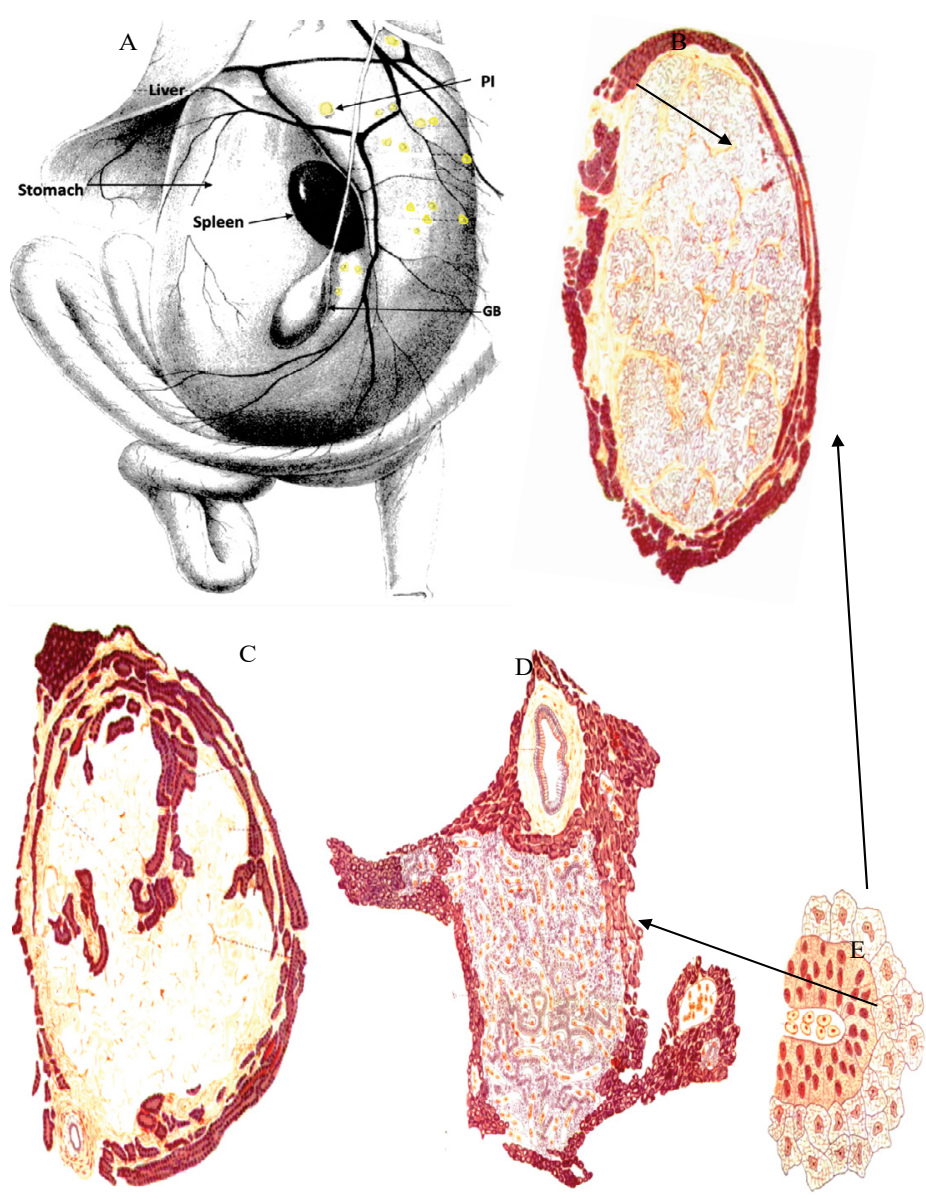

Figure 5: Because Rennie found that islets occurred separate from the exocrine gland in many teleosts, he used this feature to harvest pure islet tissue to extract the internal secretion of the tissue. A) Abdominal viscera of Lophius piscatorius, which shows the general distribution of islets (in yellow). Usually a principal islet (PI), is always the largest within the group. B) A principal islet from Anarrhichas lupus showing only a slight penetration of exocrine tissue. C) Islet from $d$ showing a greater penetration of exocrine tissue. D) Principal islet from Pleuronectes platessa showing the surrounding exocrine tissue including a large duct. E) An enlarged area of Pleuronectes, showing different appearances of the dark and light cells found all principal islets. From Rennie, 1905 Quart. J. Microsc Sci.

within the exocrine parenchyma. It was during this first decade of the 1900's that xenotransplantation of islets was further explored for its value in reversing diabetes.

\section{A Piscine Discovery}

In 1903, John Rennie a zoologist from Aberdeen University, reported his observations that the islets of teleostean fishes are found in the abdominal cavity separate from the exocrine pancreatic gland (see Figure 5). Rennie designated a consistently larger islet found among smaller aggregates in several species as the "principal islet." This principal islet, he held, reflected a phylogenic change where in higher vertebrates it would be lost while smaller accessory islets would function in its place. He utilized this unique anatomical feature to the utility of his diabetic patients. In 1907 he published a report describing five diabetic patients most of whom were administered an oral preparation consisting of either fresh, or macerated, digested and filtered piscine islets [49]. One patient received his filtered cellular prep via injection which was abandoned because of inflammatory reaction at the injection site. Because no consistent improvement was found among the patients, the unreliability of a consistent supply of islets as well as the variable patient status made conclusions indefinite.

\section{A New Method of Isolation}

Perhaps most importantly at this time was a method discovered by Ssobolev $(1902)[42,43]$ and subsequently by Gley (1905) [48] and DeWitt (1906) [50] whereby the exocrine acinar parenchyma of animals could be experimentally atrophied by blocking or ligating the pancreatic duct leaving the endocrine islets completely intact (see Figure 4 and Figure 6). This allowed preparations of pancreatic tissue free of the digestive enzymes that would make any attempt otherwise to isolate the islet component useless due to autolysis of the gland and explains in many cases why extracts of the glandular preparations were in fact ineffective. Ductal ligation would eventually be used by Banting in his isolation of the glycolytic anti-diabetic substance later designated as insulin in 1921 [51]. The importance of securing a method whereby the islet tissue which composes approximately $1-2 \%$ of the gland could be isolated from the human pancreas cannot be underestimated. Ductal ligation and other methods of exocrine atrophy which 

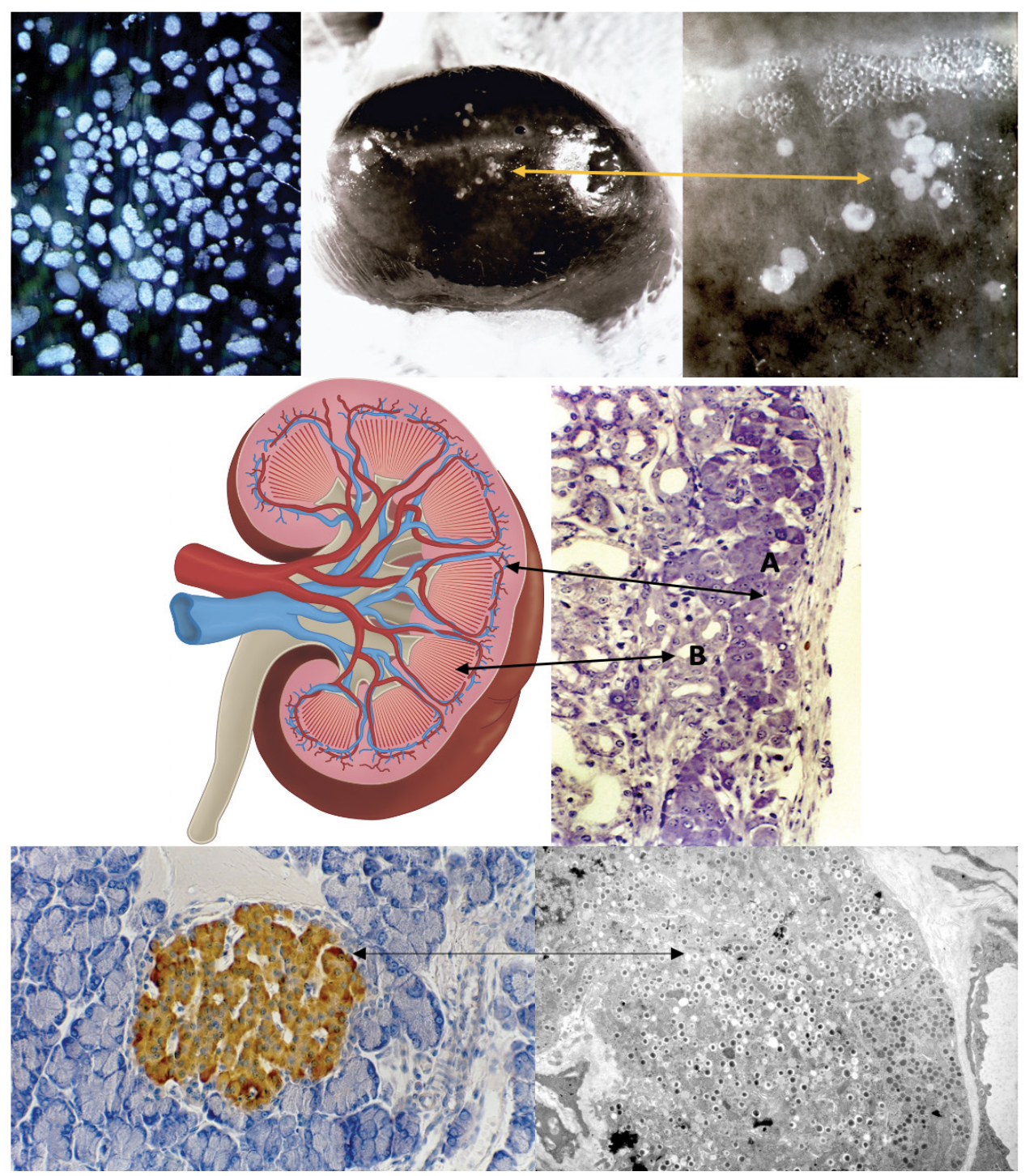

Figure 6: Top row: The atrophy model for transplanting pancreas islet tissue was largely abandoned after 1920s. Later, in the 1960s, enzyme dissociation of islets (left) made transplantation of islets possible. The kidney became one of the orthotopic locations for implantation. A) mouse kidney is shown with islets (middle and right) implanted below the renal capsule. Middle- Left and right: Islet implants below the kidney capsule (A) have access for to the rich blood supply (B) provided by the fine branches of the arcuate arteries. If tolerated, the $\beta$-cells of the islet tissue begin to response to glucose stimulation. Bottom: Left panel an islet stained for insulin appears brown in an ordinary brightfield micrograph. The color indicates the antibody-antigen linkage to the insulin granules which appear at high mag (right panel) as block dots within a single $\beta$-cell. Source of micrographs: ${ }^{\odot}$ Cyprian Weaver, 2019. Source of kidney drawing: ${ }^{\circ}$ Cynthia Faraday 2019.

exclusively eliminates the exocrine tissue leaving the islets intact allows the specific harvest of islet tissue for isolated analysis and study but transplantation as well (see Figure 4). The ligation method was used in the final efforts to transplant pancreas into the diabetic patients of this era. A xenotransplant from a duct-ligated baboon pancreas was carried out in C. Frugoni's lab in 1926 and reported by Luisada in 1927. Atrophied pancreatic tissue was transplanted beneath the tunica vaginalis of two adolescent diabetics. Definitive conclusions could not be drawn after a year other than the amount of insulin was less than what was required before because they continued to have supplemental insulin treatment [52].

\section{The Aftermath of Insulin}

The use of non-human animal substances used in the ensuing decades for testing the hormone insulin is well beyond this study. Suffice it to say, that numerous human patients were utilized in defining as well as refining the hormone biochemistry and its therapeutic applications. With the discovery of insulin in 1921 by Banting and Best (Figure 3 ), although crude in its physiological effect, came the ability to effectively regulate glycemia and ushered in an era that brought the long sought relief to the many patients afflicted with the disease. Subsequent decades focused on the synthesis and refinement of the hormone to make it safer and more effective. The fully synthetic insulin arrived in 1975 and finally its human recombinant form in the 1980's and now has a worldwide distribution in a variety of analogues which have replaced years of refining insulin from primarily porcine and bovine animal sources. Further significant progress has been made in both islet cell xenografts 
as well as human allotransplanted-based procedures which have become more of a reality after the 1950s. Methods of enzyme disaggregation which emerged and became more commonly used to achieve the goal of procuring pure preps of islet tissue for both xeno- and allotransplantation for heterotopic implantation (see $\mathrm{Fi}$ gure 6). As in the case of the thyroid, the pancreas would eventually yield its hormonal component but only in its course of being defined and characterized in its experimental application as hormone replacement therapy and not in organ replacement. No amount of surgical skill, or bravado, at this earlier point in time would have been attempted given the surgical complexity of the organ which only came in 1966 when the first clinical pancreas transplantation was successfully carried out at the University of Minnesota [53]. Nevertheless, much of the experimental dimension of pancreatic function and physiology that would be applicable to human pancreas transplantation would have its basis in non-human animals. This xenogeneic perspective has persisted to the present day in the selection of the pig not only as a source of insulin for diabetic therapy, xenotransplantation of islets which have a very similar physiology to that of humans [54,55], but as a primary species for genomic manipulation. Technical intervention now includes the use of blastocyst complementation in generating porcine pancreas in cloned dysorganogenetic embryos chimerized by pluripotent cells [56], as well as defining the role of Neurogenin 3, a transcription factor involved in endocrine pancreas development by CRISPR/Cas9 gene ablation [57], both leading toward the ultimate goal of producing human-pig chimeras for generating human organs from the pig model [58].

\section{The Lag in Diabetes Research}

In reviewing the history recounted above, many questions arise that challenge this chapter in xenotransplantation history and the pancreas. The first question that arises is why did it take so long to identify the problem of diabetes and the pancreas? Although initial reports on the palliative therapeutic effects of insulin were positive the overall clinical climate remained contentious. Professional journals reflected this disconnect as well. On the one hand, the 1923 May editorial letter in The Lancet expressed a critical assessment of the slow progress made in pancreatic diabetes with 25 years having been consumed to establish the anatomy and physiology of the islets and yet another 30 years to move from this physiological basis to applied therapeutics [59]. This is somewhat disingenuous when one considers the April issue of the preceding month in which the editorial letter thoroughly reviewed the most recent work being carried out on blood sugar including the impact of the newly discovered insulin, yet it observed that: "...it is by no means certain that diabetes is invariably a disease of the pancreas" [60].

The association of diabetes and the pancreas was not self-evident largely because of the nature of the gland itself which is both exocrine and endocrine. On the one hand its cellular parenchyma had a very dynamic role in producing potent digestive enzymes utilizing a prominent ductal system but on the other would be a totally different function - an endocrine function - that was intimately connected to the vascular circulation in the transport of the hormone. Even with the detailed transfusion experiments of Hedon (1913) designed to elaborate on the internal secretion of the pancreas and the etiology of diabetes he was forced to conclude: "We are not yet able to formulate a precise theory pancreatic diabetes; but, in my opinion, the action of the pancreas on the liver, which is undeniable, could be the only one exerted secretion internal, and its absence the only cause of diabetes, all other causes invoked being only consequences of that one" [14]. The complete picture had literally to be put together piece by piece beginning with the consistent association of capillary beds within the vascular ductless glands, the metabolic relationship between diabetes and other organs as well as the biochemistry of in the internal secretion.

\section{Competing Theories}

While some in this early period held to pancreatic theory others would not and for very good reasons. Bradford (1900) reviewing the then recent experimental investigations into the pathology of diabetes considered the etiology to be multifactorial: "...the disease diabetes is itself of mixed origin. Further, the lesions causing the malady may not only be functional or organic in nature, but even if organic they may be diverse, in one case a lesion of the liver and in another a lesion of the pancreas causing the disease" [61]. Tylden (1892) for example was critical of the theory because lesions of the pancreas were not always found in diabetic patients [62], while Weichselbaum and Stangl (1901) who prodigiously studied the islets in the pancreas of diabetics concluded at best that given some atrophic changes in the gland the quantity of islets may be diminished [63]. Hansemann (1894) in his equally systematic study of islets in an extensive pancreatic sample of diabetic patients concluded that no relationship was evident [64]. In his further study (1902) of sclerosis in the pancreas of diabetics he again found no correlation between the pathology and diabetes and concluded that: "So it seems to me to be certain that pancreatic diabetes can develop without sclerosis of the islets". He added apologetically: "I am very sorry to destroy such a tempting hypothesis without being able to provide something positive in its place, because despite my investigations the characterization of diabetes and the islets remain obscure" [65]. No doubt the latter remark was made with Opie in mind whose work was published the previous year as noted earlier. As noted above in the xenotransplanted patients of Watson Williams and James Allan the post-mortem changes indicated both gross changes in the one 
case while the gland appeared completely normal in the other case leaving the relationship undefined and ambiguous.

An initially compelling neurogenic theory largely promoted by Eduard Pflüger was competing as the cause of diabetes as well. Minkowski and Mering had deliberately performed transfusions of blood of a diabetic dog into the vein of a healthy animal to demonstrate no changes in sugar in the recipient. Furthermore, they assured their readers that the solar plexus was not injured in the operation and therefore only the extirpation was responsible for the diabetic onset [66]. Despite this supportive documentation, Plfüger, who had investigated the neural structures found within the pancreas in 1869 , attacked the experiments and held that the diabetes was due to damage to the nerves of the solar plexus [67]. It should be noted however that Langerhans himself had noted some relationship was evident between the Zellhaufen and neural elements: "..... one often sees a streak of pale nerves passing over the cell clusters (islets), but without being able to prove any connection with them; similarly, the cell clusters are not infrequently in the immediate vicinity of a ganglion; in some cases they appear to be similarly attached to the nerve trunk, as appears to be in weak enlargements with ganglion cell clusters" [68]. These microscopic observations were also later confirmed in the islets of frogs and rabbits in the work of Von Ebner (1872).

In addition to the neurogenic theory of diabetes, a lingering specter about the islet tissue itself distracted attention from its hypothetical endocrine nature to one that linked it with the lymphoid system. Several investigators at this time proposed that islet cells were a collection of lymphoid cells most notably Renault (1879), Kuhne and Lea (1882), Sokoloff (1883) to whom Ulesko noted earlier had addressed her objections and Mouret (1894), a position that had been dismissed by Langerhans himself. This was also disputed by Laguesse (1893) [32] and by Harris and Gow (1894) [69]. As noted by Hans Schadewaldt however, the lymphoid theory was largely discredited by Gentes in 1902 when he observed no discerning changes in islet cells in those patients with leukemia where hypertrophy systemically targeted lymphoid tissues [70].

\section{Transplantation Challenged}

Transplantation did not escape criticism from within the medical community in response to its use to alter the progressive course of diabetes. As noted above James Allan published a series of letters explaining his attempt to reverse the diabetic status of his patient with an xenograft of sheep pancreas [24-26]. Upon the publication of the final letter was a response from an oncologist who had followed the case, Dr. Keith Monserrat. He begins with the question: "Why transplantation? Dr. Allan will find in the literature of experimental medicine overwhelming evidence of the futility of attempting to transplant organs, or parts of organs, from one species to another. The invariable result is either sloughing or gradual absorption." Then he concludes his critique by saying that: "In face of these facts I think it quite unjustifiable to perform on a diabetic such an operation as that proposed" [71]. This was in spite of Allan's previous remarks that he had exhausted all other forms of treatment and feared to release his patient to a sure and final death. Such criticism was sufficient however to elicit a follow-up report from Allan the next year in The Lancet entitled, The Relation of the Pancreas to Diabetes and the Question of the Transplantation of that Gland as a Remedy for the Disease. In this report, he alluded to the fact that the "myxoedematous patient is pretty much in the same category and that in his case transplantation of gland has yielded happy results" [72]. He ended his argument justifying his efforts to utilize a xenotransplanted organ by reminding his readers the failure arose because the transplanted organ had atrophied and lost its effectiveness. He added a further remark that his present communication did not aim at urging the operation but to see it as a potential resort when other therapeutic interventions had proven ineffective. Actually, Monserrat castigating remarks were not founded on pancreas-based evidence but more likely on the experimental reports being published contemporaneously on thyroid implantation whose outcomes were largely negative.

\section{The Value of Self-Criticism}

A climate of healthy self-criticism did exist in this era and is often overlooked in our enthusiasm of seeing the potential buffoonery in the claimed successes of evolving medical practice. Another troublesome question arises - why, in light of the fact that pancreatic extracts, elixirs and particularly raw preparations of the animal gland did not work, did investigators persist in trying these on their patients? This criticism might best be met on a case by case basis, however highlighting some of the most notable cases may suffice. Despite the remarkable find in 1922 by Banting and his groups in Canada as well as those who would promote the subsequent use of insulin, a contentious holdout for feeding of the raw gland continued through the early decades of the $20^{\text {th }}$ century. This is best exemplified by the series of testimonials published in the British Journal of Medicine in the spring of 1925. In a letter of Dr. Thomas Hollins (March 14) he defended his continued use of feeding raw pancreas because the "raw gland seems to do all that insulin does in a diabetic (for example, hypoglycemia)" [73]. Aside from the more reliable therapeutic effects, Hollins ended by saying that while some may object that "eating of raw gland is a loathsome thing; but patients on gland treatment inform me that it forms quite a delicious meal, especially when taken with lettuce reminding us in this respect of phthisical patients on raw or very much underdone meat" [73]. Interestingly enough, a week later Dr. Young (March 28) wrote 
to express his total support for Hollins' position "even to the mincing of the gland and mixing it with lettuce" [74]. Still later, Dr. William Dunn (April 4) responded to Hollins' paper in which he adopted the regimen for one of his patients who responded with urinary normoglycemia. Dunn concluded by saying: "To my mind Dr. Hollins' discovery is of even greater practical importance that that of insulin, as it brings the treatment within the range of the mass of people, whereas insulin was only for the few" [75].

Nonetheless, two weeks later, a Dr. Harrison (April 18) declared that he had decided to repeat the experiments reported earlier under carefully controlled conditions but was unable to confirm the work of Young and Hollins. He further suggested that their positive results may have occurred in response to changes made in their diet along with the raw pancreas [76].

These negative results were echoed less than two weeks later (May 2) when Dr. Graham wrote in to report his negative results which led him to conclude that "These experiments do not hold out any hope that raw pancreas can be of any assistance to the patient with true diabetes who needs insulin" [77]. In the same issue and following Graham's letter, a Dr. Ffennell notes that Harrison used insulin in tandem with the oral administration of raw pancreas while Hollins, Dunn and Young did not and raised the question of: "What becomes of Harrison's argument? [78] Finally, in the June issue, R.D. Lawrence a diabetic who experimented on himself, concluded that some of the conflicting evidence had a reasonable basis despite the wretched nature of the therapy: "I found raw pancreas so horrible as to prefer a dozen injections a day, if necessary, and I am sure that its continued use would have made me unable to eat much else - thus providing a simple method of introducing nausea, starvation, and undernutrition into the treatment! Raw pancreas has been carefully tried before and found wanting. Though it cannot replace insulin, the slender possibility still remains that it may stimulate and cause the release of endogenous insulin in mild or moderate cases" [79].

\section{The Increasing Challenge to Find a Cure}

Although some improvement was documented, the existing state of variable outcomes, the abhorrence of eating raw animal glands, undergoing xenografting, injections of pancreatic preparations that often resulted in inflammation at the site of injection or extreme dieting - all challenged diabetology in theory as well practice. Seeing patients literally languish away before the physician's eye evoked any attempt to reverse this overwhelming syndrome at almost any cost. In light of all these attempts one can rationally see why, despite the oddity of MacNamera's suggestion of rectal administration of pancreatic derivatives, it was actually a spot on recommendation for absorption considering the fact that he was in effect suggesting a portal hepatic circuitry via the inferior mesenteric vein obviating the degradation of the hormone inherent in an oral route and eliminating the abhorrent consumption of raw glands.

One could also question the rationale of xenotransplantation of fish islets to attempt to restore normoglycemia in diabetic patients. Unexpectedly, some of the very early attempts at targeting specifically the islets of the teleostean pancreas for their therapeutic internal secretion would be revisited much later in our own modern era. Although Rennie's (1903; 07) use of the teleostean 'principal islet' tissue largely free of contaminating exocrine parenchyma was processed as an oral extract in treating diabetic patients $[49,80]$ as well as the work of Swale Vincent (1924) and others who used them in the early experimental attempts at insulin extraction [81], the idea was not lost to history. Beginning with the initial work of Weber in the 1970s [82], but particularly in the 1990s and referring back to these early studies, research on piscine Brockmann Bodies (BB) largely from Tilapia have proved useful for xenotransplantation research $[83,84]$. They have been shown effective in the longer term maintenance of normoglycemia in streptozotocin-diabetic nude mice [85-87], in the study of discordant islet cell xenotransplantation $[88,89]$, in the production of transgenic BB secreting human insulin $[90,91]$, and in studies of microencapsulation and cross-species tolerance [92]. Likewise, BB from other teleostean species have proven applicable in biochemical studies of glucosensing through glucokinase-independent mechanisms [93], as well as it gene expression in altered dietary carbohydrates both in the rainbow trout [94].

Finally, the clinical attempts to devise a therapeutic solution came in the midst of frantic investigation into and the birthing pains of endocrine research. Schlich may very well be correct in reminding transplant surgeons and medical historians that: "Before the 1880's no one had even dreamed of treating internal diseases by transplanting organs. Such an approach did not exist. There was no such thing as an ancient dream of mankind about organ transplantation" [95]. That being said implies of course that once the possibility arose the floodgates were opened and a flurry of attempts were made to make grafted restoration a reality for the betterment of patients. This was particularly true for challenging chronic diseases such as diabetes and other endocrine syndromes. Although xenotransplantation historically led the earliest surgical intervention in the pursuit of restoring lost or negligible pancreatic endocrine function, the initial attempts produced futile results. Nevertheless, the effort promoted the continued search for the elusive islet tissue that held the key to an internal secretion which maintains vital normoglycemia. The search in effect led an unprecedented era of intensive investigation into endocrine glandular function. As Rolleston notes, before 1890 the literature on ductless glands was negligible but by the time Biedl published 
his book, Die innere Sekretion (1910), it contained no less than 256 pages of bibliography with references to around 8,500 articles. Furthermore by 1925 over 3,000 articles were being published annually [96]. Endocrinology had expanded so greatly in this brief period that Means (1935) suggested it had been itself - "the target of growth hormone" [97].

\section{References}

1. Willis $T$ (1679) Pharmaceutice rationalis, or on exercitation of the operation of medicines in human bodies. T Drink, $\mathrm{C}$ Harper, J Leigh, London, UK.

2. Cullen W (1793) A Synopsis of Methodological Nosology. Parry Hall, Philadelphia, 115-116.

3. Dobson M (1776) Experiments and observations on the urine in diabetes. Medical Observations and Inquiries, London, 5: 298-316.

4. Rollo J (1797) An account of two cases of the diabetes mellitus: with remarks, as they arose during the progress of the cure to which are added, a general view of the nature of the disease and its appropriate treatment. T. Gillet, for C. Dilly, London, UK.

5. Chevreul M (1815) Note sur le sucre du diabete. Ann Chim 95: 320.

6. Bernard C (1884) De l'origine du sucre dans l'economie animale. Arch Gen d Med 18: 316

7. Joslin EP (1952) Apollinaire Bouchardat 1806-1886. Diabetes 1: 490-491.

8. Lancereaux $E$ (1877) Note et réflexions sur deux cas de diabète sucré avec alteration du pancrèas. Bull Acad Méd 6: 1215.

9. Lancereaux E (1883) Le diabéte maigre; ses symptomes, son évolution, son pronosticet son traitement; ses rapports avec les altérations du pancréas. In: Delahaye A, Lecrosnier E, Etude comparative du diabéte maigre et du diabéte gras. Leçons de Clinique Médicale, Dans, Paris, 5-16.

10. Lancereaux $E$ (1888) Nouveaux faits de diabète sucré avec alterations du pancrèas. Bull Acad Méd Communications séance.

11. von Mering JV, Minkowski O (1889) Diabetes mellitus nach Pankrcasexstirpation. Zbl Kiln Med 10: 393.

12. Lancereaux M, Thiroloix A (1892) Le diabete pancreatique. Comp Rend Hebd 115: 342.

13. Hedon ME (1892) Greffe sous-cutanée du pancréas; ses résultats au point de vue de la theorie du diabète pancréatique. $44: 679$.

14. Hedon E (1913) Sur la sécrétion interne du pancréas et la pathogénese du diabète pancrèatique. (Expériences de transfusion). Arch Intern de Physiol, 4-53, 255-288.

15. Minkowski O (1893) Untersuchungen über den Diabetes mellitus nach Exstirpation des Pankreas. Arch f Ex Path U Pharmakol 31: 85-189.

16. Harley V (1895) Pancreatic diabetes in animals and man Med Chron 3: 323.

17. Mansell-Jones R (1893) Pancreatic Juices in Diabetes," under "Notes, Letters. Br Med J 1: 50.

18. Wood $N(1893)$ The treatment of diabetes by pancreatic extracts. Br Med J 1: 64 .

19. Mackensie HWG (1893) The treatment of diabetes mellitus by means of pancreatic juice. Br Med J 1: 63-64.

20. Hale White W (1893) On the treatment of diabetes mellitus by feeding on raw pancreas and by the subcutaneous injection of liquor pancreaticus. Br Med J 1: 452-453.

21. McNamera J (1894) Suggestions for the treatment of pancreatic diabetes. Br Med J 2: 126.

22. Watson Williams $P$ (1894) Notes on diabetes treated with extract and by grafts of sheep pancreas. Brit Med $\mathrm{J} 11$ : 1303-1304.

23. Watson Williams $P$ (1903) Transplantation of pancreas in diabetes. Br Med J 1: 580.

24. Allan JW (1903) Transplantation of the pancreas in diabetes. Brit Med J 1: 711.

25. Allan JW (1903) Transplantation of the pancreas in diabetes, and of suprarenal gland in Addison's disease. Br Med J 1: 523.

26. Allan JW (1903) Transplantation of the pancreas in diabetes. Brit Med J 1: 764-765.

27. Morris, John $\mathrm{CH}$ (1988) Pioneer attempt to cure diabetes by pancreatic transplantation. Med J Aus 149: 634-636.

28. Pybus F (1924) Notes on suprarenal and pancreatic grafting. Lancet 204: 551.

29. Ottolenghi D (1901) Sur la transplantation du pancreas. Arch Ital d Biol, 454.

30. Tiberti N (1909) Sur les effets de l'extirpation partielle et de; 'extirpation totale du pancreas chez les chiens. Arch Ital d Biol 51: 131.

31. Langerhans $P$ (1869) Beiträge zur mikroskopischen Anatomie der Bauchspeicheldruse. Inaugural-Dissertation. Gustav Lange, Berlin, Germany, 274.

32. Laguesse $G$ (1893) Sur la formation des ilots de Langerhans dans le pancreas. Comp Rend Seances Mem Soc de Biol 45: 819-820.

33. Truhart H (1904) Zum ersten Ursprung der modernen Inseltheorie beim Diabetes mellitus. St. Petersb Med Woch 29: 577-578.

34. Ulesko $C$ (1883) On the structure of the pancreas during its physiological rest and action (in Russian). Vratch 21: 324.

35. J Henle (1841) Allgemeine Anatomie Lehre von den Mischungs- und Formbestandtheilen des menschlichen Körpers. Verlag von Leopold Voss, Leipzig, 114.

36. J Müller (1844) Handbuch der Physiologie des Menschen. Verlag von J Hölscher, Coblenz, Germany.

37. G. Bush, T Huxley, Kölliker's (1852) Manual of human histology. New Sydenham Society, London.

38. Murray GR (1892) Remarks on the treatment of myxoedema with thyroid juice, with notes of four cases. Br Med J 2: 449-451.

39. Brown-Séquard (1889) The effects produced on man by subcutaneous injections of a liquid obtained from the testicles of animals. Lancet, 106.

40. Brown-Séquard CE (1893) Influence heureuse de la transfusion de sang normal après l'extirpation des capsules surrenales chez le cobaye. Com Rend Biol Paris 45: 448449.

41. Schafer EA (1895) Address in physiology on internal secretions. Lancet 11: 321-324.

42. Ssobolew LW (1900) Ueber die Structure der Bauchspei- 
cheldruse unter gewissen pathologischen Bedingungen, Zet f. allge Path u Path Anat 11: 202-203.

43. Ssobolew LW (1902) Zur normalen unde pathologischen morphologies der innernsecretion der auchspeicheldruse. Die eseutung der Langerhansschen inseln. Virchows Arch 168: $91-128$

44. Sauerbeck E (1902) Lubarsh und Ostertagg. Ergebnisse der Path 11: 538.

45. Sauerbeck E (1904) Die Langerhansschen Inseln im normalen und kranken Pankreas des Menschen, insbesondere bei Diabetes mellitus. Virchows Arch, 177.

46. Opie $E$ (1901) The relation of diabetes mellitus to lesions of the pancreas. Hyaline degeneration of the islands of Langerhans. J Exp Med 5: 527-540.

47. De Meyer J (1909) Action de la secretion interne du pancreas sur differents organes et en particulier sur la secretion renale. Arch d Physiol 7: 99.

48. Gley E (1922) Action des Extraits de Pancreas Sclerose Sur des Chiens Diabetiques. Comp Rend Soc de Biol 87: 1322-1325.

49. Rennie J, Fraser T (1907) The islets of langerhans in relation to diabetes. Biochemi J 2: 7-19.

50. Dewitt LM (1906) Morphology and physiology of areas of langerhans in some vertebrates. J Exp Med 8: 193-239.

51. Banting FG (1922) The internal secretion of the pancreas. Am J Physiol 29: 479.

52. Luisada A (1927) II Diabete e La Teoria Della Fissazione Strutturale. La Reiforma Medica 43: 220.

53. Kelly WD, Lillehei RC, Merkel FK, Idezuki Y, Goetz FC (1967) Allotransplantation of the pancreas and duodenum along with the kidney in diabetic nephropathy. Surgery 61 : 827-837.

54. Crowther N, Gotfreadsen C, Moody AJ, Green IC (1989) Porcine islet isolation cellular composition and secretory response. Horm Metab Res 21: 590-595.

55. Valdes-Gonzalez R, Rodriguez-Ventura AL, White DJ, Bracho-Blanchet E, Castillo A, et al. (2010) Long-term follow-up of patients with type 1 diabetes transplanted with neonatal pig islets. Clin Exp Immunol 162: 537-542.

56. Matsunari $\mathrm{H}$, Nagashima $\mathrm{H}$, Watanabe $\mathrm{M}$, Umeyama $\mathrm{K}$, Nakano K, et al. (2013) Blastocyst complementation generates exogenic pancreas in vivo in apancreatic cloned pigs. Proc Natl Acad Sci USA 110: 4557-4562.

57. Sheets TP, Park KE, Park CH, Swift SM, Powell A, et al. (2018) Targeted mutation of NGN3 Gene disrupts pancreatic endocrine cell development in pigs. Sci Rep 8: 3582.

58. Wu J, Greely HT, Jaenisch R, Nakauchi H, Rossant J, et al. (2016) Stem cells and interspecies chimaeras. Nature 540: 51-59.

59. Anon (1923) The story of insulin. Lancet 1: 911.

60. Anon (1923) Recent work on blood-sugar. Lancet 1: 707.

61. Bradford JR (1900) Recent experimental contribution to the pathology of diabetes. The Practitioner 12: 131.

62. Tylden HJ (1892) Recent researches in diabetes mellitus. Lancet 1: 254-255.

63. Weichselbaum A, Stangl E (1901) Zur Kenntniss der feineren Veranderung des Pankreas bei Diabetes mellitus. Wiener kiln Woch 14: 968.
64. Hansemann V (1894) Die Beziehungen des Pankreas zum Diabetes. Zeit f klin Med 26: 191.

65. Hansemann V (1902) Ueber die Structur und das Wesen der Gefassinseln des Pankreas. Gesellsch, Verhandl der Deutschen path, 4: 195.

66. von Mering JV, Minkowski O (1889) Diabetes mellitus nach Pankrcasexstirpation. Zbl Kiln Med 10: 394.

67. Pfluger E (1907) Untersuchungen uber den Pankreasdiabetes. Pflugers Arch 118: 265-321.

68. Langerhans $P$ (1869) Beitrage zur mikroskpischen Anatomie der Bauchspeicheldruse. Inaug Dissert, Berlin, Germany, 281.

69. Harris VD, Gow WJ (1894) Note upon one or two points in the comparative histology of the pancreas. J Physiol 15: 349-360.

70. Schadewaldt $H$ (1989) The history of diabetes mellitus. In: Dietrich von Englelhardt, Diabetes Its Medical and Cultural History. Springer-Verlag, Berlin, Germany, 59.

71. Monsarrat K (1903) Transplantation of pancreas in diabetes. Brit Med J 1: 764-765.

72. Allan JW (1904) The relation of the pancreas to diabetes and the question of transplantation of that gland as a remedy for disease. Lancet 2: 1343-1344.

73. Hollins TJ (1925) Treatment of diabetes by raw fresh gland (Pancreas). Brit J Med 1: 503-574.

74. Young $R$ (1925) Treatment of diabetes by raw fresh gland (Pancreas). Brit J Med 1: 632.

75. Dunn W (1925) Treatment of diabetes by raw fresh gland (Pancreas). Brit J Med 1: 680.

76. Harrison GA (1925) Treatment of diabetes by raw fresh gland (Pancreas). Brit J Med 1: 760.

77. Graham G (1925) Treatment of diabetes by raw fresh gland (Pancreas). Brit J Med 1: 860.

78. Fennel EB (1925) Treatment of diabetes by raw fresh gland (Pancreas). Brit J Med 1: 860.

79. Lawrence RD (1925) Treatment of diabetes by raw fresh gland (Pancreas). Brit J Med 1: 1108.

80. Rennie J (1903) On the occurrence of a 'principal islet' in the pancreas of teleostei. J Anat Physiol 37: 375-378.

81. Vincent S, Dodds EC, Dickens F (1924) The pancreas of teleostean fishes and the source of insulin. The Lancet 204: 115-116.

82. Weber C, Weil R, Mclntosh R, Hogle H, Warden G, et al. (1975) Xenotransplantation of piscine islets into hyperglycemic rats. Surgery $77: 208-215$.

83. Yang H, Wright JR Jr (1995) A method for mass harvesting islets (Brockmann bodies) from teleost fish. Cell Transplant 4: $621-628$.

84. Nguyen TM, Wright JR Jr, Nielsen PF, Conlon JM (1995) Characterization of the pancreatic hormones from the Brockmann body of the tilapia: Implications for islet xenograft studies. Comp Biochem Physiol C Pharmacol Toxicol Endocrinol 111: 33-44.

85. Wright JR Jr, Polvi S, Maclean H (1992) Experimental transplantation with principal Islets of teleost fish (Brockmann Bodies): Long-term function of tilapia islet tissue in diabetic nude mice. Diabetes 41: 1528-1532.

86. Wright JR Jr, Pohajdak B (2001) Cell therapy for diabetes using piscine islet tissue. Cell Transplant 10: 125-143. 
87. Wright JR Jr, Yang H (1997) Tilapia brockmann bodies: An inexpensive, simple model for discordant islet xenotransplantation. Ann Transplant 2: 72-75.

88. Dickson BC, Yang H, Savelkoul HF, Rowden G, van Rooijen $\mathrm{N}$, et al. (2003) Islet transplantation in the discordant tilapia-to-mouse model: A novel application of alginate microencapsulation in the study of xenograft rejection. Transplantation 75: 599-606.

89. Wright JR Jr, Pohajdak B, Xu BY, Leventhal JR (2004) Piscine islet xenotransplantation. ILAR J 45: 314-323.

90. Pohajdak B, Mansour M, Hrytsenko O, Conlon JM, Dymond LC, et al. (2004) Production of transgenic tilapia with Brockmann bodies secreting [desThrB30] human insulin. Transgenic Res 13: 313-323.

91. Wright JR Jr, Yang H, Hyrtsenko O, Xu B-Y, Yu W, et al. (2014) A review of piscine islet xenotransplantation using wild-type tilapia donors and the production of transgenic tilapia expressing a "humanized" tilapia insulin. Xenotransplantation 21: 485-495.
92. Safley SA, Cui H, Cauffiel SM, Xu BY, Wright JR Jr, et al. (2014) Encapsulated piscine (tilapia) islets for diabetes therapy: Studies in diabetic NOD and NOD-SCID mice. Xenotransplantation 21: 127-139.

93. Otero-Rodiño C, Librán-Pérez M, Velasco C, Álvarez-Otero R, López-Patiño MA, et al. (2016) Glucosensing in liver and Brockmann bodies of rainbow trout through glucokinase-independent mechanisms. Comp Biochem Physiol B Biochem Mol Biol 199: 29-42.

94. Polakof S, Panserat S, Plagnes-Juan E, Soengas JL (2008) Altered dietary carbohydrates significantly affect gene expression of the major glucosensing components in Brockmann bodies and hypothalamus of rainbow trout. Am J Physiol Regul Integr Comp Physiol 295: R1077-R1088.

95. Schlich T (2013) The origins of organ transplantation surgery and laboratory science 1880-1930. University of Rochester Press, New York.

96. Rolleston HD (1936) The endocrine organs in health and disease - with an historical review. Oxford University, UK.

97. Means JH (1935) Internal Medicine. In: JH Musser, London, UK, 806. 